[REVIEW]

\title{
A Cognitive Linguistic Analysis of the English Imperative: With Special Reference to Japanese Imperatives
}

By Hidemitsu Takahashi, Human Cognitive Processing (HCP) 35, John Benjamins, Amsterdam, 2012, xvii $+242 p p$.

HIDEKI MORI

Fukui Prefectural University*

Keywords: English imperatives, schema, prototype, construction, force exertion

1. Introduction

A Cognitive Linguistic Analysis of the English Imperative by Hidemitsu Takahashi offers a comprehensive description and analysis of English imperatives that sheds light upon a variety of imperative data and reveals profound cross-linguistic implications. This book not only presents the findings from a series of studies he conducted during the past decade, including his dissertation submitted to Hokkaido University in 2004, but also adds new data and insights to help us gain a better understanding of imperatives from a cognitive viewpoint.

Although there are numerous studies on imperatives, according to Takahashi, they have not provided a satisfactory answer to most fundamental questions. First, previous studies have paid scant attention to the usage of imperatives in conversation or discourse, although grammatical features peculiar to imperatives such as self-controllable properties and the unacceptability of negation after be have been revealed through introspective judgments of constructed and context-free examples. Also, no previous research has offered a theoretically straightforward account of a broad range of imperative uses. Depending on the context, for example, the same imperative form can have a directive or non-directive use. In other words, it can express a variety of illocutionary forces.

* I am indebted to two anonymous reviewers of English Linguistics for their helpful comments and suggestions. All remaining errors and inadequacies are my own.

English Linguistics 30: 2 (2013) 752-764 -752-

(C) 2013 by the English Linguistic Society of Japan 
The main purpose of the book is to fill the abovementioned descriptive and theoretical gap. Imperatives investigated in this book originate from multiple sources, not only constructed examples but also dialogues from literary works and electronic corpora such as Corpus of Contemporary American English (COCA), LexisNexis Academic, and British National Corpus (BNC). Treating imperatives as a construction (i.e. a form-meaning pairing), Takahashi attempts to present an analysis based on the cognitive linguistic notions of schema and prototype, quantitatively characterizing and comparing a wide range of imperatives in terms of parameters and numerical values.

This book review is organized as follows. Section 2 outlines the book. Section 3 introduces Takahashi's key concepts for a cognitive account of English imperatives and centers on two discussions concerning Tell me about it and passive imperatives. Section 4 states some challenges faced by his framework and analysis. Section 5 is the conclusion.

\section{Overview}

This book consists of nine chapters. Chapter 1 outlines the aim, scope, theoretical background, and organization of the book. Takahashi also introduces key concepts in characterizing a variety of imperatives: the schema and prototype of English imperatives, force exertion, second person subject, and compatibility between constructions.

In Chapter 2, Takahashi observes the actual usage of imperatives found in four fictional stories: The Sky is Falling (Sidney Sheldon, 2000), The Pelican Brief (John Grisham, 1992), Malice (Danielle Steel, 1997), and The Deception (Barry Reed, 1997). The observation leads to the following findings: (i) The most frequent verbs used as imperatives are let's, tell, let, and look; (ii) Some imperative verbs such as tell, let, and give are likely to co-occur with me; (iii) Overt negative don't systematically appears with a particular class of verbs and adjectives, i.e. adversative expressions such as worry, bother, mind, rude, hard, and stupid; (iv) Such imperative forms as let's say, let me see, look, and come on serve as discourse-organizational markers or interjections.

In Chapter 3, English imperatives are considered from the cognitive linguistics viewpoint. Using six parameters (DESIRE, CAPABILITY, POWER, COST, BENEFIT, and OBLIGATION) and numerical values outlined in Chapter 1, Takahashi proposes a schema and prototype of English imperatives and adopts a new cognitive approach to imperative utterances (for details, see 
section 3.1).

Chapter 4 explains some findings from Chapter 2 in terms of the theoretical constructs introduced in Chapter 3. The combination of a particular class of expressions with me or don't results from the manifestation of the imperative prototype, which has a high degree of DESIRE and BENEFIT. Adding the first person pronoun or overt negation to a particular class of verbs and adjectives makes imperatives more desirable and beneficial. This chapter also discusses the choice between imperatives and indirect directive constructions. The speaker avoids using imperatives when the required action involves both a high COST and low OBLIGATION.

Chapter 5 is concerned with the compatibility of imperative constructions and other verb forms such as the passive, progressive, and perfective forms. Imperatives using these verbs are not acceptable because of the conceptual conflict between the prototypes of imperative constructions and each verbal construction. Those verb forms, however, can appear in the imperative construction when they are conceptually in harmony with the imperative prototype (for passive imperatives, see section 3.2).

Chapter 6 discusses conditional imperatives, which can be interpreted as if-conditional clauses and are followed by and or or. From the perspective of compatibility between constructions, Takahashi argues that andconditional imperatives are an instance of a higher-level construction, "leftsubordinating and" (Culicover and Jackendoff (1997)), but not an isolated construction. ${ }^{1}$ Similarly, or-conditional imperatives are treated as an example of a higher-level construction, "asymmetric or" (Lakoff (1971)). ${ }^{2}$ Thus, and-and or-conditional imperatives inherit the conditional feature from their

1 Left-subordinating and is exemplified by the following:

(i) a. You drink another can of beer and I'm leaving.

b. Say anything and I'll call the police.

c. One more can of beer and I'm leaving.

(Culicover and Jackendoff (1997: 197-198, 214, 196)) Despite the syntactically coordinate structure, $(\mathrm{ia}-\mathrm{c})$ have a conditional interpretation (i.e. semantic subordination). The first conjunct can be filled not only by a declarative sentence but also by a VP (i.e. imperative) or an NP, as in (ib) and (ic), respectively.

2 Two conjuncts of asymmetric or such as (i), unlike those of symmetric or, cannot be reversed without changing the target meaning:

(i) a. I want you to be quiet or the security guards will put you outside. [DECLARATIVE + DECLARATIVE]

b. Choose your financial planner wisely or (you'll) suffer the consequences. [IMPERATIVE + DECLARATIVE/IMPERATIVE]

c. Your money or your life! [NP $+\mathrm{NP}]$ 
parent constructions.

Chapter 7 further considers the compatibility of English imperatives with concessive clauses. Imperatives can appear in though, although, and except clauses, but not in even though clauses. This finding can be explained in terms of the degree of clause integration. The former three conjunctions form concessive clauses rectifying the content of a main clause, leading to loose syntactic integration, but even though has no such function and results in tight integration. Since imperatives require an independent environment, or loose clause integration, they favor the former type.

Chapter 8 presents a contrastive analysis of English and Japanese data. In particular, passive imperatives in Japanese are considered from the perspective of compatibility between the imperative prototype and that of the passive construction. The contrastive analysis suggests that in spite of morphosyntactic differences between English and Japanese imperatives, the overall idea of this book can be applied to both languages.

Chapter 9 is the conclusion, with a summary of the main findings and suggestions for future research. As for cross-linguistic implications, the book ends with examples of imperatives expressing threats, dares, or sarcasms from Russian, French, and Mandarin Chinese.

\section{Analysis}

\subsection{Key Concepts}

For a cognitive linguistic analysis of imperatives in the book, Takahashi introduces the following concepts: schema, prototype, which can numerically be measured by two criteria (force exertion and second person subject), and compatibility between constructions.

The schema of English imperatives is shown in Figure 1 (p. 13).

Figure 1: Schema of the English Imperative

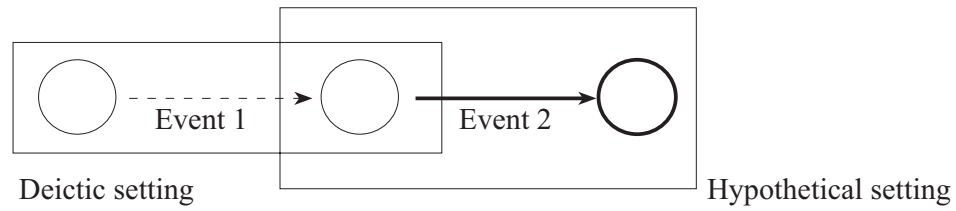

$\mathrm{S}=$ Speaker $/ \mathrm{A}=$ Addressee

Speaker's (a varying degree of) force exertion toward Addressee

Addressee's action (coded by imperative verb) 
Imperatives consist of Event 1 and Event 2: the former precedes and causes the latter. The circle on the left in Event 1 refers to the speaker who, in a deictic setting, exerts some degree of force (represented by the broken arrow) toward the addressee, portrayed as the circle in the middle. The addressee then takes action in a hypothetical setting.

Based on the schema, the imperative prototype is described as follows ( $\mathrm{p}$. 14):

(1) Prototype of the English imperative

a. The speaker exerts a high degree of force in the deictic setting toward the addressee, who will thereby perform an action in a hypothetical setting.

b. The speaker plays the semantic roles of Causer and Agent, and the individuated addressee plays the roles of Causee and Agent.

The prototype is analyzed using two criteria. ${ }^{3}$ The primary criterion is force exertion, which is defined as the "psychological influence the speaker is exerting on the addressee to cause the addressee to realize what is said" (p. 14). It is composed of six parameters (DESIRE, CAPABILITY, POWER, COST, BENEFIT, and OBLIGATION) and values, in terms of which the strength of force of a given imperative utterance can be measured and characterized. Imperatives are placed at any point between $[+10]$ (plus maximum) and [-7] (minus maximum) on the numerical scale of force exertion. Another criterion for the imperative prototype is second person subject, which is analyzed using two components: IDENTITY (individuated or generic) and SEMANTIC ROLE (causee + agentive or non-causee + non-agentive). The degree of the prototype can thus be assessed in terms of force exertion and second person subject. Table 1 shows the matrix of parameters and values (p. 88).

${ }^{3}$ By prototype, Takahashi means "an abstract representation of the conceptual core of a category," not "the central member, or the cluster of central members, of a certain category" (p. 76). Since the first definition of prototype is based on schema, the prototype in (1) is based on the imperative schema in Figure 1, central features of which are a high degree of force exertion (=(1a)) and second person subject as Agent $(=(1 \mathrm{~b}))$. 
Table 1: A Matrix of Parameters and Values Constituting the Imperative Prototype

\begin{tabular}{|c|c|c|c|c|c|}
\hline Force Exertion & HIGH & LOW & ZERO & M. LOW & M. HIGH \\
\hline a. DESIRE & {$[+2]$} & {$[+1]$} & {$[0]$} & {$[-1]$} & {$[-2]$} \\
\hline b. CAPABILITY & 1 & {$[+1]$} & {$[0]$} & I & I \\
\hline c. POWER & l & {$[+1]$} & {$[0]$} & {$[-1]$} & / \\
\hline d. $\quad$ COsT & {$[+2]$} & {$[+1]$} & {$[0]$} & I & / \\
\hline e. BENEFIT & {$[+2]$} & {$[+1]$} & {$[0]$} & {$[-1]$} & {$[-2]$} \\
\hline f. OBLIGATION & {$[+2]$} & {$[+1]$} & {$[0]$} & {$[-1]$} & {$[-2]$} \\
\hline Total score: & \multicolumn{5}{|c|}{ 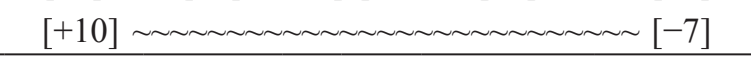 } \\
\hline $\begin{array}{l}\text { Second Person } \\
\text { Subject: }\end{array}$ & \multicolumn{2}{|c|}{$<$ PROTOTYPICAL $>$} & \multicolumn{3}{|c|}{$><$ NON-PROTOTYPCAL $>$} \\
\hline a. IDENTITY: & \multirow{2}{*}{\multicolumn{2}{|c|}{$\begin{array}{l}\text { individuated } \\
\text { Causee }+ \text { Agentive }\end{array}$}} & \multirow{2}{*}{\multicolumn{3}{|c|}{$\begin{array}{l}\text { non-individuated }>\text { generic } \\
\text { non-causee }+ \text { non-agentive }\end{array}$}} \\
\hline b. SEMANTIC ROLE: & & & & & \\
\hline
\end{tabular}

As for the correlation between the first and second criteria, imperatives with high force tend to have an individuated and agentive subject, but some imperatives with low force or without force also have an agentive subject.

Finally, along the lines of Construction Grammar (e.g. Goldberg (1995)), Takahashi regards imperatives as form-meaning pairings (i.e. constructions). $\mathrm{He}$ argues that the idea of compatibility between constructions plays a significant role in providing a unitary account of the varying acceptability of less-typical imperatives such as passive, progressive, and conditional imperatives. For example, Call me later involves imperative, transitive, and active constructions, which are all in full conceptual harmony with respect to agentivity. On the other hand, Be called later consists of imperative, transitive, and passive constructions; imperative and passive constructions are conceptually incompatible, resulting in infelicity of the form (Call me later and Be called later will be discussed contrastively in section 3.2.2).

\subsection{Case Studies}

To illustrate how his cognitive model works for English imperatives, Takahashi discusses Tell me about it in several contexts from the viewpoint of the scale of force exertion. Then, the varying degrees of felicity of passive imperatives in English are analyzed in terms of their conceptual compatibility with component constructions. These two aspects play the most significant roles throughout Takahashi's analysis. 


\subsubsection{The Scale of Force Exertion}

When the same form is used in several situations, it accordingly performs different functions. The imperative form Tell me about it, for example, appears in three distinct contexts. The following is a standard case (p. 82):

(2) [Context: A and B are coworkers and A sees that B is upset. Having no idea as to why $B$ is upset and wanting to know if $A$ can help, A addresses B]

A: What's up?

B: I'm having a bad day.

A: Tell me about it.

$\left(2^{\prime}\right)$ The Force Exertion of Tell me about it in (2)

DESIRE: [+1] or [+2]

CAPABILITY: $[+1]$

POWER: $\quad[0]$

COST: $\quad[+1] \sim[+2]$

BENEFIT: [0]

OBLIGATION: $[+1]$

TOTAL: $\quad[+4] \sim[+6]$

In the proposed scale, DESIRE is regarded as $[+1]$ or $[+2]$ because Speaker A wants his or her addressee to tell him or her about the problem, although the exact degree is not clear. Since the addressee is capable of performing the requested action, it follows that CAPABILITY is [+1]. Given no power gap between the two workers, POWER is [0]. COST, which is the addressee's psychological burden, varies depending upon how he or she feels about discussing personal matters. BENEFIT is the parameter dealing with the degree to which the speaker assumes a given action to be beneficial for the speaker and/or the addressee. In (2), BENEFIT is [0] because the action primarily benefits the addressee (the addressee's benefit is analyzed in three ways: [0], $[-1]$, and [-2]). Finally, the extent of OBLIGATION is not high because Speakers A and B are coworkers. The overall score ranges between $[+4]$ and $[+6]$.

Consider the same imperative form in a different context (p. 83):

(3) [Context: Speaker A (teacher) and Speaker B (pupil) are conversing in a classroom]

A: What's up?

B: I'm having a bad day.

A: Tell me about it. 
(3') The Force Exertion of Tell me about it in (3)

$\begin{array}{ll}\text { DESIRE: } & {[+1] \text { or }[+2]} \\ \text { CAPABILITY: } & {[+1]} \\ \text { POWER: } & {[+1]} \\ \text { COST: } & {[+1] \sim[+2]} \\ \text { BENEFIT: } & {[0]} \\ \text { OBLIGATION: } & {[+2]} \\ \text { TOTAL: } & {[+6] \sim[+8]}\end{array}$

As shown by the high total scores in (2) and (3), both imperative utterances can be considered prototypical, but two parameters differ in value from each other. Since the conversation here is between a teacher and pupil, there is a significant power gap between the two. Hence, POWER is $[+1]$ in (3). With this relationship, the pupil, in the context of the classroom, is highly obliged to comply with the teacher's direction, resulting in [+2] for OBLIGATION. The total score increases accordingly, which is consistent with our intuition that the force of imperative (3) is stronger than that of (2).

Finally, Tell me about it can also be used ironically (p. 84):

(4) [Between close friends]

A: Don't buy anything in downtown Tokyo.

B: Tell me about it. A single cup of coffee can cost 10 dollars!

(4') The Force Exertion of Tell me about it in (4)

$\begin{array}{ll}\text { DESIRE: } & {[0] \sim[-1]} \\ \text { CAPABILITY: } & {[+1]} \\ \text { POWER: } & {[0]} \\ \text { COST: } & {[0]} \\ \text { BENEFIT: } & {[0] \sim[-1]} \\ \text { OBLIGATION: } & {[-1]} \\ \text { TOTAL: } & {[0] \sim[-2]}\end{array}$

In this situation, by the imperative form Speaker B means that he or she knows about it well and does not have to be told by Speaker A. In terms of force exertion, imperative (4) is characterized by minus values. Since Speaker B does not want Speaker A to tell him or her about it, the propositional content is neither desirable nor beneficial for Speaker B. Also, given its ironic use, Speaker B does not oblige the addressee to comply; thus, oBLIGATION has a minus value.

The differences among the above three cases can be made clearer on the proposed single scale of force exertion including the involved illocutionary acts (p. 85). 
Figure 2: Illocutionary Acts of Imperatives Located on the Scale of Force Exertion

$$
\begin{aligned}
& \text { Minus maximum } \leftarrow \quad \rightarrow \text { Plus maximum }
\end{aligned}
$$

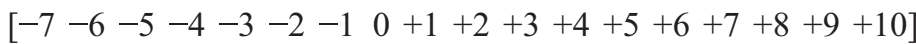

Prototypicality: LESS PROTOTYPICAL MORE PROTOTYPICAL Illocutionary Acts: IRONY REQUEST

$\begin{array}{lcc}\text { WARNING } & \text { SUGGESTION } & \text { ORDER } \\ \text { THREAT } & \text { PERMISSION } & \\ \text { DARE } & \text { CONDITION } & \end{array}$

The figure indicates that a wide range of illocutionary acts reflects varying degrees of force exertion and that not all can be sharply distinguished.

\subsubsection{Compatibility between Constructions}

Takahashi makes the following claim about mixed constructions, revealing when and how constructions are compatible (p. 123):

(5) Claims on the acceptability of mixed constructions

a. A mixed construction is analyzable as the amalgam of several distinct constructions.

b. A mixed construction is acceptable to the extent that its component constructions are compatible with one another in conceptual terms.

This claim provides a constructional account of passive imperatives' degrees of felicity. A typical imperative in (6) consists of imperative, transitive, and active constructions (p. 123):

(6) Call me later.

To the extent that all share the conception of an agentive subject entity that acts on another object entity, the three component constructions are conceptually compatible. Consider an infelicitous example (p. 124):

(7) ?Be called later.

Expression (7) is the amalgam of imperative, transitive, and passive constructions, but the imperative and passive constructions are incompatible with respect to agentivity. Prototypically, the semantic role of imperative subjects is agentive, whereas that of passive subjects is patient. This semantic conflict between the two constructions makes passive imperative (7) sound unnatural. Hence, Takahashi puts forward hypothesis (8) (p. 126): 
(8) The passive construction clashes with the imperative not syntactically but on conceptual grounds; i.e., the conflict occurs between prototypes.

Expression (7) is odd because imperative and passive prototypes conflict conceptually.

Further, one can predict that the passive fits in well with the imperative construction when there is no such conflict between each prototype (p. 127):

(9) Be checked over by a doctor, then you'll be sure there's nothing wrong.

In (9), because of the context "then you'll be sure there's nothing wrong," the imperative can easily be regarded as a request, which exerts a strong directive force. The passive subject, which is prototypically patient, is coerced into an agentive entity by the constructional meaning of the imperative. This is the cognitive operation of "Result for Action" metonymy (Panther and Thornburg (1998)). In (9), the passive imperative reads as "Do something (i.e. Go to a hospital) so that as a result you'll be checked over by a doctor." Deviation from the prototype avoids the conceptual conflict between the two component constructions.

\section{Challenges}

Takahashi's book is quite informative for the researchers of imperatives and cognitive linguists, because his analysis plays an active role as a guiding force in studies of imperatives, and contributes richly to the fields of cognitive linguistics and Construction Grammar. Specifically, the force exertion scale based on six parameters with numerical values reveals and compares varying degrees of prototypicality among different types of imperatives. Such a numerical approach has not been attempted in the previous research on imperatives. His constructional view of imperatives also opens up the possibility that imperatives can be analyzed in conjunction with other (major) types of constructions in terms of constructional compatibility, thus situating imperative research within the more general cognitive linguistics and constructional approaches. The applicability and validity of a cognitive linguistic approach are well demonstrated by Takahashi's analysis in this volume. To prompt future research and further development of the current framework, the remainder of this section presents three challenges.

First, the position of illocutionary acts of negative imperatives on the scale of force exertion is still unclear. Takahashi has not presented a complete analysis of negative imperatives in terms of the scale in this volume, 
although the relevant study can be seen in his earlier work (Takahashi (1992)). Consider an imperative in two different contexts:

(10) a. [Addressee is chatting] Don't chat in class.

b. [Addressee is not chatting] Don't chat in class.

The negative imperative of (10a) functions to prohibit the addressee from chatting at the moment of utterance. That of (10b), on the other hand, serves as an advance warning not to chat in class. If negative imperatives can be discussed on the same scale as shown in Figure 2, the difference between (10a) and (10b) should be reflected in the difference in illocutionary acts on the scale, such as prohibition vs. precaution. ${ }^{4}$ Notice that the difference in question results mainly from the reality status of the propositional content, i.e., whether or not the addressee is chatting when the speaker utters imperative (10). Without this parameter, illocutionary acts of negative imperatives cannot be discerned. The scale with the current six parameters may be sufficient for a description of illocutionary acts of positive imperatives, but it is not fine-grained enough to treat positive and negative imperatives as a whole.

Next, Takahashi attempts a force exertion analysis of Japanese imperatives as one of the cross-linguistic implications of his theoretical framework, but this needs further data collection and analysis. For instance, Takahashi discusses Japanese counterparts of Tell me about it in terms of the proposed scale, to be sure, but when it comes to mixed constructions, he compares only passive imperatives in Chapter 8. In Chapter 5, as English mixed constructions, he considers passive, progressive, and perfective imperatives within the force exertion model. An integrated analysis with progressive and perfective imperatives such as (11a) and (11b) would more precisely reveal the degree to which force exertion and constructional compatibility can be applied to Japanese imperatives:

a. Sanji-ni kokode mat-te-iro. [progressive imperative]
three-at here wait-and-be.Imp
'Be waiting here at three o'clock.'
b. Zoozei-maeni shinsha-o ka-tte-shimae.
tax increase-before new car-Acc buy-and-put away.Imp [perfective imperative]

'Be sure to have bought a new car before the tax increase.'

4 Takahashi (1992) argues that don'ts used in these two types differ in the speaker's epistemic stance, i.e. "Real-World-Position" vs. "Unreal-World-Position."

5 The abbreviations are as follows: Acc (accusative); Dist (distant from speaker and hearer); Imp (imperative); Pass (passive). 
Finally, the discussion on compatibility between constructions could benefit from a typological study of a wider range of languages. According to Takahashi's framework, the imperative and passive prototypes are not conceptually in harmony, and thus, either or both must depart from their prototypes in order to combine with each other. As stated earlier, passive imperatives cannot be prototypical. However, imperatives in Maori (an indigenous language in New Zealand) appear in the passive form whenever a transitive verb is used. Bauer (1993: 32) states that "[t]he imperative of a transitive verb requires the passive verb form, and the underlying DO [= direct object] promoted to subject." Compare imperatives (12a) and (12b):

$$
\begin{aligned}
& \text { a. E tuu! } \\
& \text { Imp stand } \\
& \text { 'Stand!' } \\
& \text { b. Patu.a te kurii raa! } \\
& \text { beat.Pass the dog Dist } \\
& \text { 'Beat that dog!' }
\end{aligned}
$$

Imperative (12a) involves an intransitive verb, whereas imperative (12b) uses a transitive verb that should appear in the passive. If there is no conflict between the imperative and passive prototypes in Maori, a comprehensive study of Maori passives could facilitate a further examination of Takahashi's hypothesis in (8).

\section{Conclusion}

From Takahashi's well-defined framework and its cross-linguistic applicability, one can conclude that this volume should be of great help and importance to researchers in the field of cognitive linguistics. In view of the significance of his work, the challenges here may seem trivial; Takahashi's new approach to English imperatives lays a firm foundation for future research and should lead to a better understanding of the meaning and function of imperatives.

\section{REFERENCES}

Bauer, Winifred (1993) Maori, Routledge, London and New York.

Culicover, Peter W. and Ray Jackendoff (1997) "Semantic Subordination despite Syntactic Coordination," Linguistic Inquiry 28, 195-217.

Goldberg, Adele E. (1995) Constructions: A Construction Grammar Approach to Ar- 
gument Structure, University of Chicago Press, Chicago.

Lakoff, Robin (1971) "If's, And's and But's about Conjunction," Studies in Linguistic Semantics, ed. by Charles Fillmore and Terence Langendoen, 114-149, Holt, Reinhart and Winston, New York.

Panther, Klaus-Uwe and Linda L. Thornburg (1998) "A Cognitive Approach to Inferencing in Conversation," Journal of Pragmatics 30, 755-769.

Takahashi, Hidemitsu (1992) "Negative Imperatives," The Annual Report on Cultural Science 40, 149-167.

[received December 17 2012, revised and accepted April 29 2013]

Center for Arts and Sciences

Fukui Prefectural University

4-1-1 Matsuoka Kenjojima, Eiheiji-cho, Yoshida-gun

Fukui 910-1195

e-mail: hmori@fpu.ac.jp 